\title{
Measuring the importance of local food in the Chicago foodshed
}

\author{
Steven R. Miller ${ }^{\mathrm{a}}$ and John T. Mann ${ }^{\mathrm{b}}$ * \\ Michigan State University
}

Submitted May 6, 2019 / Revised June 28 and July 29, 2019 / Accepted July 29, 2019 / Published online January 20, 2020

Citation: Miller, S. R., \& Mann, J. T. (2pp020). Measuring the importance of local food in the Chicago foodshed. Journal of Agriculture, Food Systems, and Community Development, 9(2), 101-122. https://doi.org/10.5304/jafscd.2020.092.008

Copyright (C) 2020 by the Authors. Published by the Lyson Center for Civic Agriculture and Food Systems. Open access under CC-BY license.

\begin{abstract}
The study is motivated by the need to develop cost-effective tools to estimate the value and size of local food systems. Organizations in need of such evaluations often cannot afford the large price tag for the type of in-depth analysis they desire, and thus alternative, cost-effective methods are the next best choice. We use a recent evaluation of the Chicago foodshed to demonstrate one such costeffective tool. Expansion of local sales constitutes import substitution, where local foods supplant existing imports. The proposed input-output (I/O) modeling method combines a "follow the money" approach with one that isolates total contributions of the local food systems, and uses an alternative definition of local foods. The approach modifies the underlying IMPLAN data and uses secondary data to account for other changes. The method is

\footnotetext{
a Steven R. Miller, Assistant Professor, Department of Agricultural, Food, and Resource Economics, and Director, Center for Economic Analysis, Michigan State University.

$\mathrm{b} *$ Corresponding author: John T. Mann, Assistant Professor, Department of Agricultural, Food, and Resource Economics; Justin S. Morrill Hall of Agriculture; 446 W. Circle Drive, Room 88; East Lansing, MI 48824-1039 USA; +1-517-3552153; mannjoh3@msu.edu
}

applied to a multicounty region comprising four states; the method's limitations are also discussed.

\section{Keywords}

Local Food Systems, Input-Output Model, Import Substitution, IMPLAN

\section{Introduction}

A major challenge for local food system (LFS) advocates is managing the intersection of policy, measurement of economic impacts, and practice. There is a growing body of literature that applies different methods to measure the economics of LFSs; some examples include Conner et al., 2013; Jablonski, Schmit, and Kay, 2016; Mann et al., 2018; Miller et al., 2015. Civic leaders apnd program managers wish to know how their efforts contribute over time, but impact studies are not able to provide sufficient monitoring to gauge progress or failure toward meeting common targets for LFSs. For policy-makers and advocates, the absence of estimates of the size of an LFS hinders the monitoring and evaluation of the importance of the LFS on local economies.

Because the size of an LFS is difficult to assess, many previous economic impact studies limited 
their focus to key local foods outlets such as farmers markets or food hubs (Henneberry, Whitacre, \& Agustini, 2009; Hughes, Brown, Miller, \& McConnell, 2008; Jablonski et al., 2016; O’Hara \& Pirog, 2013; Otto \& Varner, 2005). These survey methods are difficult to implement and can be costly, and concluding such studies' estimates of the size of an LFS falls short of capturing the size and economic value of the broader LFS that may span well beyond direct-to-consumer sales (Low et al., 2015; O'Hara \& Pirog, 2013). It is also difficult to generalize outcomes due to differences in economic and environmental factors underlying the data collection. On the opposite spectrum, recent studies have set out to establish the potential size of LFSs under the hypothetical scenario that consumers meet the U.S. Department of Agriculture (USDA) recommended dietary guidelines through local foods (Conner et al., 2013; Conner, Knudson, Hamm, \& Peterson, 2008). While this approach is highly replicable and regional estimates are comparable across studies, it may also face criticism, for example, in terms of defining local foods or the availability of less aggregated data sources when smaller regional units are of interest. At the same time, the use of secondary data, where possible, is attractive when budgets directed to measuring LFSs are small.

More recently, Shideler and Watson (2019) demonstrated the use of the Local Food Impact Calculator (LFIC), a tool intended for noneconomists that provides a basic impact measure given responses to a few simple questions. The LFIC uses a production-based on LFS assumptions and relies on the 2014 Agriculture Resources Management Survey data to develop the traditional input-output (I/O) multiplier. While a costeffective and efficient tool, there may be more complex scenarios such that organizations interested in evaluating their LFS need additional guidance and assistance to address. Additionally, some scenarios may incorporate secondary data or information that these organizations have little practical experience using.

This article is motivated by an interest in devel- oping inexpensive baseline measures of the size of LFSs for the purposes of monitoring and evaluating program outcomes. ${ }^{1}$ More specifically, we estimate the size of the LFS using the same underlying software used to estimate its economic impacts. As such, we demonstrate how standard economic I/O models can provide a low-cost, replicable estimate of the baseline of broader regional food systems. These estimates can be the basis for measuring changes in and economic impacts of LFSs. This study also breaks new ground by providing a net assessment of the size and contribution of an LFS within a major metropolitan area, specifically a 38county region that includes the Chicago metropolitan area (which comprises counties across four states). Estimates in this study are limited by excluding the contribution of livestock agriculture and meat processing, which may have a material impact on the true size of the LFS (Low et al., 2015; Martinez et al., 2010). To accomplish the goals of this study, we restrict our definition of local food to food produced and consumed in a region regardless of the marketing channel used to reach consumers. What follows is a brief discussion of the use of the I/O modeling applied to LFSs, a description of the methods and strategies employed in this study, a discussion of results, and, finally, a few concluding remarks.

\section{Previous Research}

While the literature on local food has grown significantly over the past two decades, a number of unresolved challenges that affect the framework, results, and policy implications of such studies remain. This examination of the Chicago study region is not an exception, as the two major hurtles encountered include defining the LFS and the methods used to estimate the size of it. The main issue is the interconnectedness between the definition of local food and the specific method for measuring the system. The current literature does not provide a clearly delineable definition of what constitutes local food (Hand \& Martinez, 2010; Low et al., 2015; Martinez et al., 2010). Increasingly, elements of the supply chain's local orienta-

\footnotetext{
1 This motivation is in line with broader efforts intended to help improve rural entrepreneurial and innovations ecosystems, thus increasing rural economic opportunities (Lyons, Miller, \& Mann, 2018).
} 
tion, such as large verses small firms, may also influence definitions (Low et al., 2015; Thilmany McFadden, 2015). For example, Thilmany McFadden (2015) points out that definitions may be further securitized as more corporate farms enter the local foods arena and local food consumers increasingly expect that their values and those of the corporate farms be more closely aligned. For analysts, data limitations (and budget constraints) in measuring the impact often dictate the definition and approach used to measure the economic impacts of LFSs (Miller et al., 2015).

The most recent attempts to measure LFSs have approached the issue from one of two general frameworks: (1) methods that allow for flexible definitions; and (2) definitions facilitated by specific modeling methods. Defining an LFS by the specific goods offered in the region's farmers markets and consumed locally asserts that data requirements for estimating the LFS accurately reflects the unique basket of goods and region that provides it (Hughes et al., 2008; Otto \& Varner, 2005). However, collecting such data is labor- and cost-intensive, and contextually specific to the LFS studied. As a result, such data is not widely available and findings cannot be generalizable outside of the study region.

Most studies investigating the impact of LFSs set the basis of analysis on directly measurable local food transactions, like direct-to-consumer (DTC) sales at farmers markets or community supported agriculture (CSAs). Such studies generally show a positive return for farmers as compensation for taking on the marketing effort of directly selling to consumers (Brown, 2002; Low \& Vogel, 2011; Martinez et al., 2010). That is, they are able to capture the trade margins that farms earn that would otherwise be captured by wholesalers and retailers. However, studies that estimate economic impacts based on local food sales often overlook two offsetting effects (Boys \& Hughes, 2013; Hughes, et al., 2008; Hughes \& Boys, 2015). First, growers who sell through local channels give up potential revenues by not selling through conventional channels (Swenson, 2010). Second, consumer expenditures on local foods imply a reduction of expenditures on foods through conventional channels (Boys \& Hughes, 2013; Hughes, et al., 2008;
Hughes \& Boys, 2015; Schmit, Jablonski, \& Mansury, 2013). Studies that fail to account for these offsetting effects implicitly assume that (1) all local food sales are derived from new production; and (2) all conventional food sales are imports with no local intermediation (Lee, Miller, \& Loveridge, 2017). Once accounting for these offsetting effects, the net economic impacts will be much smaller, to the extent that the overall impact may be smaller than the actual value of the local food making up the LFS (Boys \& Hughes, 2013; Hughes, et al., 2008; Hughes \& Boys, 2015).

Researchers are in the early stage of exploring methods for holistically measuring the value of LFS that entails direct-to-consumers, intermediated channels, and processed-food channels to consumers. This coincides with advances in access to secondary data on local food sales that promise to be more inclusive than one-off, survey-based venue data. Low and Vogel (2011) used the ongoing farm-level survey data from the Agricultural Resource Management Survey (ARMS), collected and provided by the USDA, to estimate DTC sales, with the limitation that it omits intermediated and processor sales. The USDA National Agricultural Statistics Service (USDA NASS) has made promising inroads in understanding the structure of LFSs through the Local Food Marketing Practices Survey of the Census of Agriculture (conducted every five years). This survey expands the definition of local food transactions beyond DTC by also addressing sales to restaurants, food hubs, and others (USDA NASS, 2015), but is limited to recognizing differences in farm-level production practices between conventional and small, localoriented producers. Despite being an improvement in access to farm-level data for representation of LFSs, the data are still limited in defining the local food as that sold through conventionally defined local food channels and fails to recognize the full extent of the local food production and processing captured in the local economy.

Studies on the economic impacts of LFS often rely on the IMPLAN economic simulation software and data (Çela, Knowles-Lankford, \& Lankford, 2007; Cooke \& Watson, 2011; Henneberry, Whitacre, \& Agustini, 2009; Hughes et al., 2008; Jablonski, Schmit, \& Kay, 2016; Miller et al., 2015; 
Otto \& Varner, 2005). IMPLAN's default model parameters represent the production practices and household purchases patterned after national averages across all firms. However, LFS researchers recognize that participants in LFSs exhibit purchasing and selling behavior that may differ significantly from the conventional food systems that dominate IMPLAN's parameters (Hughes et al., 2008; Jablonski, Schmit, \& Kay, 2016; Swenson, 2009). Jablonski and Schmit (2016) caution that standard production functions underlying IMPLAN will not be representative of differences in the value chains between local and conventional food channels. This concern about the appropriateness of national coefficients for representing local food systems is not unique to LFS researchers. Lazarus, Platas, and Morse (2002) show that regional variations in hog production may erode estimate precision of regional hog production using IMPLAN's national parameters. Despite known deficiencies in using nationally parameterized IMPLAN production functions, IMPLAN remains a mainstream resource for estimating economic impacts of LFS. Thus, it may also make sense to apply the same tool for estimating economic impacts to that of estimating the overall size of the LFS.

Methods for augmenting national I/O parameters for regionalized models are well established (Jackson, 1998). Hughes, Brown, Miller, and McConnell (2008) advocated for more research on estimating the unique production attributes of smaller farms with DTC sales. More recently, Jablonski and Schmit (2016) set out to modify IMPLAN's regionalized I/O table to reflect local farm practices selling direct-to-consumers in New York using proprietary and USDA survey data. A recent toolkit commissioned by the USDA Agricultural Marketing Service (USDA AMS) details the practices and standards for effective economic impact estimates of local food systems (Thilmany McFadden et al., 2016). In that toolkit, the topic of augmenting standard IMPLAN data to reflect small producer production practices is relegated to an advanced modeling section for the initiated. Finally, Conner, Becot, and Imrie (2016) highlight the challenges in applying these prescribed advanced modeling techniques, noting steep data requirements and the resistance of suppliers along the value chain to participate in primary data collection efforts.

The approach applied in this study does not focus on agri-food channels conventionally categorized as making up the LFS, but rather tracks all channels by which food produced in the local economy comes to be consumed in the local economy. This includes DTC and intermediated sales, as well as sales arising through processed foods. Hence, rather than focusing this study on modifications to the agri-food production functions that fit the local food mantra, our study is limited in focus to the application for measuring the size, not the impact, of local food systems. Further, it applies the same software used for estimating impacts to estimating the size of the local food system and is consistent with the data used to estimate impacts. Given the study methods, this also means that the definition of local is restricted geographically to the study region. That is, all food produced and consumed in the study regions, regardless of marketing channel (from DTC to conventionally produced foods that wind up being consumed within the study region). Thus, this definition may deviate from more traditional ways in which some think about local food. ${ }^{2}$ Unfortunately and based on the design of the approach, this is one major limitation. However, the approach used here can accommodate researchers wishing to apply more stringent definitions of "local" through modifications of the transactions table. This step is outside the scope of this study.

\section{Methods}

We used IMPLAN to estimate the size of the LFS, and this was the basis for estimating the LFS's economic impacts and for gauging changes over time. We believe this approach affords consistency with the underlying data. It is also consistent with how

2 As an example, consider a tomato used for manufacturing ketchup. Conceivably, a tomato may be produced, processed, and consumed all in the same region. While this example may adhere to a strict geographical definition of local, as Thilmany McFadden (2015) points out, this type of definition may not match up other characteristics or perceptions about locally produced food. 
local food is defined in this study — as that which is produced, processed (if applicable), and ultimately consumed in the same region, regardless of the channel used to reach final the consumers. This definition assumes that locally sourced food traversing conventional food channels is as much a part of the LFS as that sold through DTC channels, such as farmers markets, CSAs, etc.

The approach used in this study was developed by combining aspects of several prior studies, including Conner et al., (2008), Cooke and Watson (2011), Miller at al., (2015), Swenson (2009), Thilmany McFadden et al., (2016), Watson, Cooke, Kay, and Alward (2015), and Watson, Kay, Alward, Cooke, and Morales (2017). Due to the technical nature of the discussion on the approach, we include a more detailed description of the methods in an appendix. We also believe the information provided in the appendix is relevant to those interested in replicating our effort, although that is outside the main objective of this study.

\section{Study Region Data}

The LFS study region is made up of 38 counties around and including Chicago, where 14 counties make up the Chicago-Joliet-Naperville IL-IN-WI Core Based Statistical Area (CBSA). The county I/O data came from 2013 state packages for Illinois, Indiana, Michigan, and Wisconsin (which make up the LFS region) for use with IMPLAN Pro 3.1 (IMPLAN Group LLC, 2015). However, data accounting for changes are discussed in more detail in the next paragraph, and modifications to the underlying I/O model were discussed in the previous section and subsections. All 38 counties were aggregated into a single region for analysis, and the model was closed up to the household level. ${ }^{3}$ To facilitate calculations, sectors were aggregated into 2-digit NAICS categories. However, crop-producing sectors were broken out, and a second manufacturing category was created from manufacturing for food processing sectors. This allowed the analysis to isolate intermediate agricul- tural purchases for food processing from those for non-food manufacturing. The sector aggregation is presented in Table 1. It is notable that a sizeable portion of grain production in the study region tends to go toward nonfood manufacturing sectors.

We collected additional data for assessing agricultural production from multiple USDA sources (USDA, 2012, 2013; USDA Economic Research Service, 2016; USDA Farm Service Agency, 2016; USDA NASS, 2013; USDA NASS Cropland Data Layer, 2016). These data provided the agricultural production statistics by county for comparing with IMPLAN transactions, and highlighted regions where specialty crops are grown. Specialty crops are particularly interesting from an LFS perspective because they are more closely aligned with local food channels than commodity-type row crops like corn and soybeans (Martinez et al., 2010). Unfortunately, there are many omissions in the NASS data collection, which become more pronounced at finer geographic granularity. We found that the USDA NASS Cropland Data Layer for 2015 was most useful for identifying regions of crop production, but it also has shortcomings in accuracy of the size of acres in any commodity category and in the ability to identify small fields of commodity production (Han, Yang, Di, \& Yue, 2014; USDA NASS Cropland Data Layer, 2016). Regardless, the Cropland Data Layer indicates that a significant portion of the area's agricultural fields is in soybeans and corn production. Consistent with the Cropland Data Layer distinguishing sweet from dent corn, county-level USDA Farm Service Agency (USDA FSA) data show that in 2015 about $0.1 \%$ of planted corn acres in the model region had intended use as fresh, while grain, seed and processed were the most common intended uses by far (USDA FSA, 2016). That is, a significant share of corn production in the region will not go toward human consumption as sweet corn.

\footnotetext{
${ }^{3}$ Counties included in Illinois: Boone, Cook, DeKalb, DuPage, Ford, Grundy, Iroquois, Kane, Kankakee, Kendall, La Salle, Lake, Lee, Livingston, McHenry, Ogle, Will, and Winnebago; in Indiana: Elkhart, Jasper, Kosciusko, Lake, LaPorte, Marshall, Newton, Porter, Pulaski, St. Joseph, and Starke; in Michigan, Berrien, Cass, and Van Buren; in Wisconsin, Jefferson, Kenosha, Milwaukee, Racine, Walworth, and Waukesha.
} 
The Cropland Data Layer shows that specialty crops, like vegetables, melons, and fruit, are grown throughout the region and are often intermixed with row crop acreage. While largely dispersed, there are regions where specialty crops tend to co-locate. Specifically, the crop profile in southwest Michigan, including Berrien, Cass, and Van Buren counties, reflects significant clustering of grapes, cherries, apples, and blueberries. Other specialty crops appear but with less dominance, including cucumbers, dry beans, celery, and asparagus. On the other side of Lake Michigan and south of Milwaukee is another area with specialty crop clusters. These clusters include cabbage, greens, and dry beans, among others. In summary, there were some 7 million acres (2.8 million hectares) planted to crops in the modeling region in 2015, where specialty crops made up less than $2 \%$ of that acreage. This sizeable acreage is primarily allocated to row-crop production of corn
Table 1. Model Aggregates

\begin{tabular}{|c|c|}
\hline Model Industry Aggregates & 30 Food Processing \\
\hline $11 \mathrm{Ag}$, Forestry, Fish \& Hunting & Flour milling \\
\hline Grain farming & Rice milling \\
\hline Vegetable and melon farming & Malt mfg \\
\hline Fruit farming & Wet corn milling \\
\hline Tree nut farming & Soybean and other oilseed processing \\
\hline Greenhs., nrsry., \& floriculture & Fats and oils refining and blending \\
\hline 21 Mining & Breakfast cereal mfg \\
\hline 22 Utilities & Beet sugar mfg \\
\hline 23 Construction & Sugar cane mills and refining \\
\hline 31-33 Manufacturing & Non-chocolate confectionery mfg \\
\hline 30 Food Processing & Chocolate and confectionery mfg from cacao beans \\
\hline 42 Wholesale Trade & Confectionery mfg from purchased chocolate \\
\hline 44-45 Retail trade & Frozen fruits, juices and vegetables $\mathrm{mfg}$ \\
\hline 48-49 Transportation \& Warehousing & Frozen specialties mfg \\
\hline 51 Information & Canned fruits and vegetables $\mathrm{mfg}$ \\
\hline 52 Finance \& insurance & Canned specialties \\
\hline 53 Real estate \& rental & Dehydrated food products $\mathrm{mfg}$ \\
\hline 54 Professional- scientific \& tech svcs & Fluid milk mfg \\
\hline 55 Management of companies & Creamery butter mfg \\
\hline 56 Administrative \& waste services & Cheese mfg \\
\hline 61 Educational svcs & Dry, condensed, and evaporated dairy product mfg \\
\hline 62 Health \& social services & Ice cream and frozen dessert mfg \\
\hline 71 Arts- entertainment \& recreation & Animal, except poultry, slaughtering \\
\hline 72 Accommodation \& food services & Meat processed from carcasses \\
\hline 81 Other services & Rendering and meat byproduct processing \\
\hline \multirow[t]{14}{*}{92 Government \& non NAICs } & Poultry processing \\
\hline & Seafood product preparation and packaging \\
\hline & Bread and bakery product, except frozen, mfg \\
\hline & Frozen cakes and other pastries mfg \\
\hline & Cookie and cracker mfg \\
\hline & Dry pasta, mixes, and dough mfg \\
\hline & Tortilla mfg \\
\hline & Roasted nuts and peanut butter mfg \\
\hline & Other snack food mfg \\
\hline & Coffee and tea $\mathrm{mfg}$ \\
\hline & Flavoring syrup and concentrate mfg \\
\hline & Mayonnaise, dressing, and sauce $\mathrm{mfg}$ \\
\hline & Spice and extract mfg \\
\hline & All other food $\mathrm{mfg}$ \\
\hline
\end{tabular}


and soybeans. However, it provides a sizeable foodshed for feeding Chicago residents. ${ }^{4}$

\section{Results}

\section{Estimated Local Food Benchmarks}

Table 2 shows local uses and production for the Chicago study area as reported by tracing the data through the transactions aggregated regional table, as described in the Methods section. In addition to sales, Table 2 reports other key measures of economic activity, including employment, labor income, and contributions to gross regional product. Starting with the Sales/Output column, which provides estimates of the value of production and uses at producer's prices, the four crop-producing sectors generated an estimated US $\$ 3.97$ billion in output in 2013. About US $\$ 2.52$ billion was exported outside the region for consumption or processing, leaving US\$1.46 billion for local uses. This implies

Table 2. Estimated Baseline Local Foods Economics

\begin{tabular}{|c|c|c|c|c|}
\hline & $\begin{array}{l}\text { Sales/Output } \\
\text { (US } \$ 000,000 s)\end{array}$ & Employment & $\begin{array}{c}\text { Earnings } \\
\text { (US } \$ 000,000 \text { s) }\end{array}$ & $\begin{array}{c}\text { GRP } \\
\text { (US } \$ 000,000 s)\end{array}$ \\
\hline Total Output & $3,973.3$ & 16,635 & 316.5 & 193.8 \\
\hline Less Exports & $2,515.0$ & 10,079 & 160.5 & 57.4 \\
\hline Contribution to Import Substitution & $1,458.3$ & 6,556 & 156.0 & 136.5 \\
\hline Local Supply to Food Processors & 644.3 & 2,835 & 57.6 & 41.1 \\
\hline \multicolumn{5}{|l|}{ Local Fresh } \\
\hline Households & 134.77 & 1,114 & 61.1 & 89.2 \\
\hline Retail/Wholesale & 0.03 & 0 & 0.0 & 0.0 \\
\hline Food Service & 2.66 & 16 & 1.0 & 1.4 \\
\hline Institutions & 2.71 & 14 & 0.7 & 0.9 \\
\hline Total Local Fresh & 140.16 & 1,145 & 62.7 & 91.5 \\
\hline \multicolumn{5}{|l|}{ Local Processed } \\
\hline Households & 101.67 & 210 & 13.1 & 22.2 \\
\hline Retail/Wholesale & 0.20 & 0 & 0.0 & 0.0 \\
\hline Food Service & 21.66 & 45 & 2.8 & 4.7 \\
\hline Institutions & 6.44 & 13 & 0.8 & 1.4 \\
\hline Total Local Processed & 129.97 & 268 & 16.8 & 28.4 \\
\hline \multicolumn{5}{|l|}{ Total (Local Fresh + Local Processed) } \\
\hline Households & 236.44 & $1,324.37$ & 74.20 & 111.37 \\
\hline Retail/Wholesale & 0.23 & 0.66 & 0.04 & 0.06 \\
\hline Food Service & 24.32 & 61.13 & 3.78 & 6.15 \\
\hline Institutions & 9.15 & 27.20 & 1.50 & 2.30 \\
\hline Total Local & 270.13 & 1,413 & 79.5 & 119.9 \\
\hline
\end{tabular}

Note: Columns may not sum due to rounding.

Sources: IMPLAN and authors' calculations.

${ }^{4}$ Further framing issues were uncovered through anecdotal evidence provided by interviews with several Chicago area wholesale distributors specializing in local food channels. Accordingly, wholesalers suggest that growers selling through wholesale intermediaries generally do not receive price premiums over other channels. In other words, local food premiums earned by farmers are not necessarily earned only through direct selling to final uses. Rather, growers can earn premiums by selling commodity mixes sought by different local food channels. In this, those growers willing to work with specialty wholesalers to provide those difficult to market crops, can find a willing buyer. Low competition for such locally grown specialty crops not commonly supplied in this region, like lettuce, can yield returns to successful growers. 
that roughly $37 \%$ of the Chicago study region production is consumed or processed locally. Of this, about US $\$ 0.64$ billion is sold to local food processors.

Raw or unprocessed plant-based foods have two mutually exclusive channels for local consumption: unprocessed (fresh) or processed. In addition to the US $\$ 644.3$ million raw foods purchased by processors, local households purchased US $\$ 134.8$ million, food services purchased US $\$ 2.7$ million, institutions purchased US $\$ 2.7$ million, and about US $\$ 30,000$ is earned in retail and wholesale margins. ${ }^{5}$ The local foods' share of locally processed foods amounted to US $\$ 101.7$ million purchased by households, US $\$ 21.7$ million by food service, and US $\$ 6.4$ million by institutions. In total, households spent about US $\$ 270.1$ billion in locally sourced fresh and processed foods.

IMPLAN provides fixed ratios to output for estimating employment, labor income, and contributions to annual gross regional product. Accordingly, expected direct employment in the Chicago study region limited to local foods is about 1,413 , with annual income topping US\$79.5 million.

Finally, total local food output from farm to household generates about US\$119.9 million to the gross regional product.

The IMPLAN data also allow us to estimate the total household expenditures for food, for comparison with other estimates. Here, only household expenditures on crop products and processed foods are considered. According to a recent study, residents in the Chicago study region purchase about US $\$ 19.9$ billion in fresh and processed foods (USDA NASS, 2015), where about $1.4 \%$ is provided by local suppliers of crops. In a similar analysis for the state of Michigan, Miller et al. (2015) found that local sources supplied about 17\% of Michigan food demand. ${ }^{6}$ This comparison is briefly discussed in the next section.

\section{Relative Economic Contributions}

Findings in this section draw heavily from the work of Watson et al. $(2015,2017)$, and the methods were presented in the Methods section. Table 3 shows the distribution of sector sales, where intermediate sales are as related to other producing industries. The local final sales column shows the value of purchases that consumers make at the producers' prices. For grains, this largely would be

Table 3. Sector Demand Profiles (all in US\$ Millions)

\begin{tabular}{lccccc}
\hline & $\begin{array}{c}\text { Intermediate } \\
\text { Sales }\end{array}$ & $\begin{array}{c}\text { Local Final } \\
\text { Sales }\end{array}$ & $\begin{array}{c}\text { Total Local } \\
\text { Sales }\end{array}$ & External Sales & Output \\
\hline Ag, Forestry, Fish \& Hunting & $1,827.4$ & 106.7 & $1,934.1$ & $2,124.8$ & $4,058.9$ \\
Grain farming & $1,048.3$ & 24.8 & $1,073.1$ & $2,655.1$ & $3,728.2$ \\
Vegetable and melon farming & 26.5 & 82.8 & 109.3 & 25.9 & 135.2 \\
Fruit farming & 32.5 & 26.7 & 59.2 & 48.4 & 107.6 \\
Tree nut farming & 0.3 & 0.4 & 0.7 & 1.5 & 2.3 \\
Greenhouse, nursery, and floriculture & 57.3 & 78.2 & 135.5 & 162.4 & 297.9 \\
Food Processing & 5,010 & 6,322 & 11,332 & 28,726 & 40,059 \\
\hline
\end{tabular}

Source: IMPLAN and authors' calculations.

\footnotetext{
${ }^{5}$ Retail and wholesale margins may posit a conservative fallacy of strictly relying on the regional transactions table for allocating expenditures, as such margin estimates are largely weighted toward the low-margin conventional food channels. Based on conversations with wholesalers and distributors in the Chicago study region, we believe these baseline margins for locally sourced foods are low.

${ }^{6}$ Note that this includes DTC as well as conventionally produced and marketed foods that remained in Michigan for consumption. The authors point out that the definition used for this study is strictly geographic: food produced and consumed within the state bounders. However, the authors do not necessarily advocate for this definition of local. To put this value into context and using the 2015 Local Food Marketing Practices Survey and NASS Michigan Field Office data, total DTC in 2015 accounted for roughly 4.4\% of all food produced in Michigan. If this value were consistent in the 2012 (the year of the referenced study), it implies that just under $13 \%$ of the locally produced and consumed food in Michigan came from conventional sources.
} 
whole corn purchases that may take place directly from the grower, or through an intermediary, and are reported as prices the grower receives. The total local sales are the sum of intermediate and local final sales. External sales reflect exports from the region. Output is the sum of total local and external sales. Evident in Table 3 is that grain farming and food processing sales are largely driven by external purchases, as external sales accounts for roughly $71 \%$ of output. This is one potential explanation for the stark difference in the proportion of local food shares in the state Michigan (17\%) compared to the Chicago study region (1.4\%) (Miller et al., 2015). The Chicago study region has a high concentration of grain production, whereas Michigan has greater shares of specialty crops, although much of the Chicago region grain production is not for human consumption. Another aspect is the high population density compared to number of acres allocated to farming. With less farm output per capita, the Chicago-area food system is more reliant on food imports than the state of Michigan.

While Table 3 reports direct effects, Table 4 shows the sector impact distribution through secondary effects. The direct base column depicts exogenous, or export sales. The indirect base consists of secondary transactions to other sectors in the Chicago study region required in producing the agricultural commodities or processed foods. As export sales drive these secondary transactions, the sum of the direct and indirect base is the total economic base or the export base. The local purchases column is the sum of intermediate (industry purchases) and household purchases for local output. The ratio gives an indication of the extent that the sector supplies external markets relative to local markets. As demonstrated in the Table 3, it is also clear in Table 4 that grain production is much more tied to external markets, while vegetable and melon farming production is directed toward local uses in higher proportions. ${ }^{7}$

\section{Estimated Impact of a $10 \%$ Increase in Local Uses}

Next, we perform a hypothetical analysis of changes in local demand and assess how such changes will impact the Chicago study region's economy. Crop sector farm total export sales are decreased by $10 \%$ and added to by local sector purchases in proportion to current baseline purchases such that there is no net change in local crop production. Table 5 shows the simulated change in sales by the agricultural sector. In this example, both intermediate and local final uses of agricultural crops increase by $10 \%$. However, no assumption is made on changes in intermediate and final demand for local processed foods. The findings highlight the importance of recognizing the dynamic relationship of the production function to changes in local demands.

Table 4. Base versus Gross Output (US\$ Millions)

\begin{tabular}{lrrrrr}
\hline & Direct Base & Indirect Base & Total Base & $\begin{array}{c}\text { Local } \\
\text { Purchases }\end{array}$ & $\begin{array}{c}\text { Ratio } \\
\text { TB/LP }\end{array}$ \\
\hline Ag, Forestry, Fish \& Hunting & $2,124.8$ & $1,570.3$ & $3,695.1$ & $4,058.9$ & 0.91 \\
Grain farming & $2,655.1$ & $2,644.8$ & $5,299.9$ & $3,728.2$ & 1.42 \\
Vegetable and melon farming & 25.9 & 19.4 & 45.3 & 135.2 & 0.33 \\
Fruit farming & 48.4 & 38.2 & 86.6 & 107.6 & 0.80 \\
Tree nut farming & 1.5 & 1.2 & 2.7 & 2.3 & 1.20 \\
Greenhouse, nursery, and floriculture & 162.4 & 143.6 & 306.0 & 297.9 & 1.03 \\
Food Processing & $28,726.0$ & $22,814.0$ & $51,540.0$ & $40,059.0$ & 1.29 \\
\hline
\end{tabular}

Source: IMPLAN and authors' calculations.

\footnotetext{
${ }^{7}$ A more detailed examination of fruit farming reveals that high concentrations of grape production occur in eastern counties. Similarly, the core of blueberry, cherry, and apple production occur in the three counties of Southeast Michigan that are included in the region. The nature of this concentration, just as the nature of grain production concentration throughout the region, likely favors export markets.
} 
Table 5. Scenario Changes in Sales (US\$ Millions)

\begin{tabular}{lrr}
\hline & \multicolumn{2}{c}{ Change in Sales (\$ millions) } \\
\cline { 2 - 3 } & \multicolumn{1}{c}{ Local } & \multicolumn{1}{c}{ Exports } \\
\hline Grain farming & $1,073.1$ & $-1,073.1$ \\
Vegetable and melon farming & 109.3 & -109.3 \\
Fruit farming & 59.2 & -59.2 \\
Tree nut farming & 0.7 & -0.7 \\
\hline Total & $1,242.4$ & $-1,242.4$ \\
\hline
\end{tabular}

Source: IMPLAN and authors' calculations.

Table 6. Net Sales Impacts (US\$)

\begin{tabular}{|c|c|}
\hline Sector & Output Impact \\
\hline $11 \mathrm{Ag}$, Forestry, Fish \& Hunting & 8,756 \\
\hline Grain farming & 269,824 \\
\hline Vegetable and melon farming & 2,058 \\
\hline Fruit farming & 480 \\
\hline Tree nut farming & 6 \\
\hline $\begin{array}{l}\text { Greenhouse, nursery, and floriculture } \\
\text { production }\end{array}$ & 27 \\
\hline 21 Mining & 336 \\
\hline 22 Utilities & 7,857 \\
\hline 23 Construction & 7,384 \\
\hline 31-33 Manufacturing & 42,661 \\
\hline 30 Food Processing & 1,344 \\
\hline 42 Wholesale Trade & 25,601 \\
\hline 44-45 Retail trade & 7,809 \\
\hline 48-49 Transportation \& Warehousing & 13,464 \\
\hline 51 Information & 6,518 \\
\hline 52 Finance \& insurance & 37,598 \\
\hline 53 Real estate \& rental & 47,570 \\
\hline 54 Professional- scientific \& tech svcs & 12,562 \\
\hline 55 Management of companies & 3,633 \\
\hline 56 Administrative \& waste services & 6,094 \\
\hline 61 Educational svcs & 2,272 \\
\hline 62 Health \& social services & 11,167 \\
\hline 71 Arts- entertainment \& recreation & 1,833 \\
\hline 72 Accommodation \& food services & 4,781 \\
\hline 81 Other services & 5,174 \\
\hline 92 Government \& non NAICs & 3,372 \\
\hline Total Sales Net Effect & 530,182 \\
\hline
\end{tabular}

Sources: IMPLAN and authors' calculations.
Table 6 shows the sector-by-sector net impacts of simulations described in the Methods section, indicating that the total impact of diverting US $\$ 1.242$ billion in exports for local consumption generates a net change of US\$530,182 in local sales. This estimate includes both direct and secondary transactions. As may be expected, the largest source of net impacts is the grain in the farming sector, largely stemming from the significant share of the direct change in transactions. It may be unrealistic to assume that Chicago consumers will absorb US $\$ 1.073$ billion in new, unprocessed grain production. However, processors that use grains in producing milled products may have some capacity to increase purchases from local sources. Additionally, a change in local demand from the Agriculture, Forestry, Fish and Hunting sector was not modeled, yet it is evident they benefit from this change. This may occur, as the sector often provides services and inputs in the crop production sector. Other sectors also experience a change in sales as the transactions reverberate throughout the economy.

Applying fixed ratios for employment, earnings, and gross regional product to output, Table 7 reports standard economic impact metrics. Here, the US $\$ 530,182$ net change in sales is expected to give rise to about 2.4 regional jobs with annual labor income of US\$94,301. The jobs created are expected to generate annual wages of about US $\$ 39,751$. Additionally, this simulation shows contributions to gross regional product will grow by about US\$150,267.

\section{Identification of Important Sectors}

The goal of the next step is to select the most relevant industry sectors in terms of local foods, while

\section{Table 7. Summary of Impacts}

\begin{tabular}{lr}
\hline Regional Measure & \multicolumn{1}{c}{ Value } \\
\hline Change in Sales & $\$ 530,182$ \\
Change in Employment & 2.4 \\
Change in Labor income & $\$ 94,301$ \\
Change in GRP & $\$ 150,267$ \\
Average annual earnings & $\$ 39,751$ \\
\hline
\end{tabular}

Source: IMPLAN and authors' calculations. 
maintaining as simplified a model as possible.

Thus, we limit consideration to changes in model inputs per unit of output (i.e., technical coefficients) of the key food purchasing industries and of households for the five agricultural producing sectors. We successively increase the sector demand for locally produced agri-food products by $20 \%$ and measure the percent change in all industry sector multipliers, ${ }^{8}$ weighted by the sector output. These findings are reported in Table 8. Results indicate that increasing local food processing purchases of grain farming output by $20 \%$ generates relatively larger secondary effects than increasing wholesale or retail purchases. Here, increasing food processor purchases will likely result in a $10.1 \%$ increase in overall multipliers of the Chicago study region. This compares with approximately no change in multipliers for the two trade sectors. Alternatively, higher-income household purchases tend to generate larger economywide impacts than lower-income household purchases. This mostly reflects scale effects, where higher-income house holds purchased US $\$ 5.53$ million from local grain farming in 2013, compared to US\$0.7 million for the lowest-income group. Hence, a $20 \%$ increase in the higher income group constitutes a much larger direct effect change in local demand than the same for the low-income group.

Figure 1 shows the effect graphically from a $20 \%$ change in household purchases, largely reproducing the household agri-food impacts shown in Table 8. It is evident that directing local grain outputs to households is likely to generate smaller impacts than promoting local fruit, vegetables, and nut output.

As is evident in Figure 1, impacts are largest for higher-income groups, where higher income groups tend to exhibit higher aggregate expenditures in the Chicago study region. Table 9 shows the IMPLAN baseline expenditures of the commodity types by household type, showing a near uniform increase in total expenditures with higher

Table 8. Percent Change in Aggregate Multipliers Corresponding to Row Changes in Demand for Column Commodities

\begin{tabular}{lccccc}
\hline & Grain farming & $\begin{array}{c}\text { Vegetable and } \\
\text { melon farming }\end{array}$ & Fruit farming & Tree nut farming & Food Processing \\
\hline Food Processing & 10.1105 & 1.9431 & 4.0146 & 3.1077 & 4.5826 \\
Wholesale Trade & 0.0000 & 0.0015 & 0.0033 & 0.0056 & 0.0817 \\
Retail trade & 0.0015 & 0.0015 & 0.0035 & 0.0056 & 0.0277 \\
Educational svcs & 0.0358 & 0.1071 & 0.0190 & 0.0236 & 0.8750 \\
Health \& social services & 0.0083 & 0.1191 & 0.0037 & 0.0061 & 2.1583 \\
Arts- entertainment \& recreation & 0.0015 & 0.0201 & 0.0280 & 0.0446 & 0.2413 \\
Accommodation \& food services & 0.0388 & 0.2552 & 0.0406 & 0.0534 & 6.4642 \\
\hline Households $<$ US $\$ 10 \mathrm{k}$ & 0.0065 & 0.0843 & 0.0617 & 0.0884 & 0.1516 \\
Households US $\$ 10-15 \mathrm{k}$ & 0.0070 & 0.0864 & 0.0629 & 0.0926 & 0.1524 \\
Households US $\$ 15-25 \mathrm{k}$ & 0.0350 & 0.4363 & 0.3188 & 0.4623 & 0.7788 \\
Households US $\$ 25-35 \mathrm{k}$ & 0.0596 & 0.6932 & 0.5111 & 0.7183 & 1.2644 \\
Households US $\$ 35-50 \mathrm{k}$ & 0.1336 & 1.5519 & 1.1512 & 1.5768 & 2.8792 \\
Households US $\$ 50-75 \mathrm{k}$ & 0.2999 & 3.3239 & 2.4966 & 3.2503 & 6.3702 \\
Households US $\$ 75-100 \mathrm{k}$ & 0.2895 & 3.1565 & 2.3936 & 2.9866 & 6.2062 \\
Households US $\$ 100-150 \mathrm{k}$ & 0.4168 & 4.2272 & 3.2456 & 3.8515 & 8.5544 \\
Households US $\$ 150 \mathrm{k}+$ & 0.4638 & 3.9861 & 3.1158 & 3.4874 & 8.3376 \\
\hline
\end{tabular}

Sources: IMPLAN and authors' calculations.

\footnotetext{
${ }^{8}$ Households are assumed to not generate multiplier impacts but rather increase direct demand for agri-food output and hence generate secondary impacts measured in the multiplier changes.
} 
income groups. To verify this observation, regression equations (results not shown) were estimated by commodity of the results in Figure 1 against the total expenditures in Table 9, and show a close association between household category baseline expenditures and changes in the corresponding multipliers.

\section{Summary and \\ Conclusions}

The impetus of this research arose from a request to build talking points around the economic merit and feasibility of expanding Chicago's LFS. The research approach was directed at overcoming some of the obstacles for measuring LFSs and has relevance to modeling the economic impact of regional import substitution programs in general. A framework for measuring the value of LFSs, estimating the relative economic contribution of LFSs, and setting policy targets for expanding such systems is outlined within a standard I/O framework. Our secondary goal is to contribute to the growing body of literature that uses secondary data to model an LFS by providing an example that includes a multicounty region made up of parts of several states and scenarios affecting the size of the LFS.

The findings suggest that a small share of total nonprotein food consumption in the 38-county region that makes up the Chicago study area is sup-
Table 9. Baseline Household Purchases of Local Agri-food Production (US\$ Millions) by Household Income

\begin{tabular}{lcccc}
\hline & $\begin{array}{c}\text { Grain } \\
\text { farming }\end{array}$ & $\begin{array}{c}\text { Vegetable } \\
\text { and melon } \\
\text { farming }\end{array}$ & Fruit farming & $\begin{array}{c}\text { Tree nut } \\
\text { farming }\end{array}$ \\
\hline Households < US\$10k & 0.704 & 2.910 & 0.910 & 0.017 \\
Households US\$10-15k & 0.498 & 1.953 & 0.607 & 0.012 \\
Households US\$15-25k & 1.325 & 5.235 & 1.633 & 0.031 \\
Households US\$25-35k & 1.482 & 5.464 & 1.720 & 0.032 \\
Households US\$35-50k & 2.335 & 8.597 & 2.722 & 0.049 \\
Households US\$50-75k & 4.144 & 14.552 & 4.665 & 0.080 \\
Households US\$75-100k & 3.677 & 12.706 & 4.112 & 0.068 \\
Households US\$100-150k & 5.072 & 16.306 & 5.342 & 0.084 \\
Households US\$150k+ & 5.528 & 15.093 & 5.026 & 0.074 \\
\hline
\end{tabular}

Source: IMPLAN. plied by local sources. We then simulated an increase in local food demand across all sectors and households and gauged the economic impact where local food purchases supplant export sales in a one-to-one ratio. Net impacts were calculated based on changes in the underlying transactions table. The results suggest that local food is likely a weak driver of economic growth in the study region, which is a large urban center.

The approach outlined in this article also con- 
siders some of the challenges identified by past efforts at measuring the economics of LFSs. First, we adhere to a strict geographic definition of local. More specifically, the approach includes all channels by which food may traverse from grower to consumer and addresses the critique that local foods assessments fail to capture intermediate channels to consumers (Low et al., 2015). Thus, the definition of local includes channels beyond more traditional ideas in term of local foods, such as farmers markets, CSAs, etc. Second, in measuring the contribution of LFSs to the larger economy, a full accounting of opportunity costs was captured within the estimated equations. Finally, the analysis is not limited to final uses but rather establishes a framework for interpreting the value of intermediate demands and indirect channels that local food traverses to final consumption. The approach applied here can be readily applied to any defined geography, and it establishes a framework for measuring not just the impact but the actual size of the local food system, allowing practitioners to develop a baseline by which to measure changes over time.
A major limitation of this study, however, is that the transactions data used in the I/O model rely heavily on traditional marketing channels data and that distinct value chains of local food channels are not captured. Thus, results should be considered with caution. Future efforts applying this or a similar approach may want to address this shortfall. However, the framework applied is flexible enough to facilitate measuring LFSs under different definitions of what constitutes local food. As IMPLAN does not break out value chains of local food from conventional channels, the underlying data must be modified to reflect the selected definition of local food.

One direction for future research may include integrating livestock production into the local food baseline estimates. This study did not include direct measures of livestock production that make up the local food chain, in part because of the intertwined relationships of crop production as livestock feed used in livestock production. Prior work suggests that livestock production may make up a sizable component of LFSs.

\section{References}

Boys, K. A., \& Hughes, D. W. (2013). A regional economics-based research agenda for local food systems. Journal of Agriculture, Food Systems, and Community Development, 3(4), 145-150. https://doi.org/10.5304/jafscd.2013.034.012

Brown, A. (2002). Farmers' market research 1940-2000: An inventory and review. American Journal of Alternative Agriculture, 17(4), 167-176. Retrieved from https://www.cambridge.org/core/journals/american-journal-of-alternative-agriculture

Casler, S. D., \& Hadlock, D. (1997). Contributions to change in the input-output model: The search for inverse important coefficients. Journal of Regional Science, 37(2), 175-193. https://doi.org/10.1111/0022-4146.00050

Çela, A., Knowles-Lankford, J., \& Lankford, S. (2007). Local food festivals in Northeast Iowa communities: A visitor and economic impact study. Managing Leisure, 12(2-3), 171-186. https://doi.org/10.1080/13606710701339470

Conner, D., Becot, F., \& Imrie, D. (2016). Critical reflections on the USDA local food economics toolkit. Journal of Agriculture, Food Systems, and Community Development, 7(2), 117-125. https://doi.org/10.5304/jafscd.2017.072.001

Conner, D., Becot, F., Hoffer, D., Kahler, E., Sawyer, S., \& Berlin, L. (2013). Measuring current consumption of locally grown foods in Vermont: Methods for baselines and targets. Journal of Agriculture, Food Systems, and Community Development, 3(3), 83-94. https://doi.org/10.5304/jafscd.2013.033.004

Conner, D. S., Knudson, W. A., Hamm, M. W., \& Peterson, H. C. (2008). The food system as an economic driver: Strategies and applications for Michigan. Journal of Hunger and Environmental Nutrition, 3(4), 371-383. https://doi.org/10.1080/19320240802528849

Cooke, S. \& P. Watson (2011). A comparison of regional export enhancement and import substitution economic development strategies. Journal of Regional Analysis and Policy, 41(1), 1-15. Retrieved from https://jrap.scholasticahq.com

Han, W., Yang, Z., Di, L., \& Yue, P. (2014). A geospatial web service approach for creating on-demand cropland data layer thematic maps. Transactions of the ASABE, 57(1), 239-247. https://doi.org/10.13031/trans.57.10020 
Hand, M. S., \& Martinez, S. (2010). Just what does local mean? Choices, 25(1), 13-18. Retrieved from http://www.choicesmagazine.org/

Henneberry, S. R., Whitacre, B., \& Agustini, H. N. (2009). An evaluation of the economic impacts of Oklahoma farmers markets. Journal of Food Distribution Research, 40(3), 64-78. https://doi.org/10.22004/ag.econ.99760

Hewings, G. J. D. (1984). The role of prior information in updating regional input-output models. Socio-Economic Planning Sciences, 18(5), 319-336. https://doi.org/10.1016/0038-0121(84)90040-5

Hughes, D. W., \& Boys, K. A. (2015). What we know and don't know about the economic development benefits of local food systems. Choices, 30(1), 1-6. Retrieved from http://www.choicesmagazine.org/

Hughes, D. W., Brown, C., Miller, S., \& McConnell, T. (2008). Evaluating the economic impact of farmers' markets using an opportunity cost framework. Journal of Agricultural and Applied Economics, 40(1), 253-265. https://doi.org/10.1017/S1074070800028091

IMPLAN Group LLC. (2015). IMPLAN Pro (version 3.1). Retrieved December 30, 2015, from http: / $/$ www.implan.com/index.php?option $=$ com content\&view $=$ article\&id $=153 \& I t e m i d=1702$

Jablonski, B. B. R., \& Schmit, T. M. (2016). Differential expenditure patterns of local food system participants. Renewable Agriculture and Food Systems, 31(2), 139-147. https://doi.org/10.1017/S1742170515000083

Jablonski, B. B. R., Schmit, T. M., \& Kay, D. (2016). Assessing the economic impacts of food hubs on regional economies: A framework that includes opportunity cost. Agricultural and Resource Economics Review, 45(1), $143-172$. https://doi.org/10.1017/age.2016.9

Jackson, R. W. (1998). Regionalizing national commodity-by-industry accounts. Economic Systems Research, $10(3), 223-238$. https://doi.org/10.1080/762947109

Lazarus, W. F., Platas, D. E., \& Morse, G. W. (2002). IMPLAN's weakest link: Production functions or regional purchase coefficients? Journal of Regional Analysis and Policy, 32(1), 33-47. Retrieved from https://irap.scholasticahq.com

Lee, G.-E., Miller, S. R., \& Loveridge, S. (2017). Modelling local food policy and greenhouse gas emission due to transportation. Journal of Regional Analysis and Policy, 47(1), 75-87. Retrieved from https://jrap.scholasticahq.com

Lindall, S., Olson, D., \& Alward, G. (2006). Deriving multi-regional models using the IMPLAN national trade flows model. Journal of Regional Analysis and Policy, 36(1), 76-83. Retrieved from https:/ /jrap.scholasticahq.com

Low, S. A., Adalja, A., Beaulieu, E., Key, N., Martinez, S., Melton, A., ... Jablonski, B. B. R. (2015). Trends in U.S. local and regional food systems: A report to Congress (Report No. AP-068). Washington, D.C.: U.S. Department of Agriculture Economic Research Service. Retrieved from https://www.ers.usda.gov/publications/pub-details/?pubid=42807

Low, S. A., \& Vogel, S. J. (2011). Direct and intermediated marketing of local foods in the United States (Economic Research Report No. 128). Washington, D.C.: U.S. Government Printing Office. https://doi.org/10.2139/ssrn.2114361

Lyons, T. S., Miller, S. R., \& Mann, J. T. (2018). A new role for land grant universities in the rural innovation ecosystem? Journal of Regional Analysis and Policy, 48(2), 32-47. Retrieved from https://jrap.scholasticahq.com

Mann, J., Miller, S., O’Hara, J., Goddeeris, L., Pirog, R., \& Trumbull, E. (2018). Healthy food incentive impacts on direct-to-consumer sales: A Michigan example. Journal of agriculture, Food Systems, and Community Development, 8(1), 97112. https://doi.org/10.5304/jafscd.2018.081.006

Martinez, S., Hand, M., Da Pra, M., Pollack, S., Ralston, K., Smith, T., .. Newman, C. (2010). Local food systems:Concepts, impacts, and issues (Report No. ERS-97). Washington, D.C.: U.S. Department of Agriculture Economic Research Service. Retrieved from https://www.ers.usda.gov/webdocs/publications/46393/7054 err97 1 .pdf?v=0

Miller, R. E., \& Blair, P. D. (2009). Input-output analysis: Foundations and extensions. Cambridge, UK: Cambridge University Press. https://doi.org/10.1017/CBO9780511626982

Miller, S. R., Mann, J., Barry, J., Kalchik, T., Pirog, R., \& Hamm, M. W. (2015). A replicable model for valuing local food systems. Journal of Agricultural and Applied Economics, 47(4), 441-461. https:/ / doi.org/10.1017/aae.2015.19

O’Hara, J. K., \& Pirog, R. (2013). Economic impacts of local food systems: Future research priorities. Journal of Agriculture, Food Systems, and Community Development, 3(4), 35-42. https://doi.org/10.5304/jafscd.2013.034.003

Otto, D., \& Varner, T. (2005). Consumers, vendors, and the economic importance of Iowa farmers' markets: An economic impact survey analysis. (Leopold Center Pubs and Papers No. 145). Retrieved from Iowa State University Digital Repository website: https:/ /ib.dr.iastate.edu/cgi/viewcontent.cgi?article=1146\&context=leopold pubspapers 
Round, J. I. (1983). Nonsurvey techniques: A critical review of the theory and the evidence. International Regional Science Review, 8(3), 189-212. https://doi.org/10.1177/016001768300800302

Schmit, T, M., Jablonski, B. R. R., \& Mansury, Y. (2013). Impacts of local food system activities by small direct-to-consumer producers in a regional economy: A case study from upstate NY (Working paper 2013-16). Ithaca, New York: Charles H. Dyson School of Applied Economics and Management, Cornell University. Retrieved from http://publications.dyson.cornell.edu/research/researchpdf/wp/2013/Cornell-Dyson-wp1316.pdf

Sherman, J., \& Morrison, W. J. (1950). Adjustment of an inverse matrix corresponding to a change in one element of a given matrix. The Annals of Mathematical Statistics, 21(1), 124-127. https://doi.org/10.1214/aoms/1177729893

Shideler, D., \& Watson, P. (2019). Making change through local food production: Calculating the economic impact of your local food project. Journal of Agriculture, Food Systems, and Community Development, 8(Suppl. 3), $165-177$. https://doi.org/10.5304/jafscd.2019.08C.011

Stevens, B. H., Treyz, G. I., Ehrlich, D. J., \& Bower, J. R. (1983). A new technique for the construction of non-survey regional input-output models. International Regional Science Review, 8(3), 271-286. https://doi.org/10.1177/016001768300800306

Swenson, D. (2009). Investigating the potential economic impacts of local foods for Southeast Iowa (Leopold Center Publications and Papers No. 66). Ames: Iowa State University. https://lib.dr.iastate.edu/leopold pubspapers/66

Swenson, D. (2010). The economic impact of fruit and vegetable production in southwest Iowa considering local and nearby metropolitan markets (Leopold Center Publications and Papers No. 65). Ames: Iowa State University. https://lib.dr.iastate.edu/leopold pubspapers/65

Thilmany McFadden, D. (2015). What do we mean by “local foods"? Choices, 30(1), 1-6. Retrieved from http://www.choicesmagazine.org/

Thilmany McFadden, D., Conner, D., Deller, S., Hughes, D., Meter, K., Morales, A., . . Tropp, D. (2016). The economics of local food systems: A toolkit to guide community discussions, assessments and choices. Washington, D.C.: USDA, Agricultural Marketing Service. Retrieved from https://www.ams.usda.gov/publications/content/economics-local-foodsystems-toolkit-guide-community-discussions-assessments

Tiebout, C. M. (1956). The urban economic base reconsidered. Land Economics, 32(1), 95-99. https://doi.org/10.2307/3159580

U.S. Department of Agriculture (USDA). (2012). 2012 Census of Agriculture: County Profile. Washington, D.C.: Government Publishing Office.

USDA. (2013). 2012 Census of Agriculture: State level data. Washington, D.C.: Government Publishing Office.

USDA Economic Research Service. (2016). Food prices and spending. Retrieved September 9, 2019, from http://www.ers.usda.gov/data-products/ag-and-food-statistics-charting-the-essentials/food-prices-andspending.aspx

USDA Farm Service Agency (USDA FSA). (2016). Crop acreage data. Retrieved from https://www.fsa.usda.gov/newsroom/efoia/electronic-reading-room/frequently-requested-information/crop-acreage-data/index

USDA National Agricultural Statistics Service (USDA NASS). (2015). 2015 Local Food Marketing Practices Survey. Retrieved from https://www.nass.usda.gov/Surveys/Guide to NASS Surveys/Local Food/index.php

USDA NASS. (2013). 2012 Census of Agriculture. Table 1. State summary highlights: 2012. Washington, D.C.: USDA. Retrieved from https://www.nass.usda.gov/Publications/AgCensus/2012/Full Report/Volume 1, Chapter 2 County Level/

USDA NASS Cropland Data Layer. (2016). Published crop-specific data layer. Washington, D.C.: USDA-NASS. Retreived from https://www.nass.usda.gov/Research_and_Science/Cropland/SARS1a.php

Waters, E. C., Weber, B. A., \& Holland, D. W. (1999). The role of agriculture in Oregon's economic base: Findings from a social accounting matrix. Journal of Agricultural and Resource Economics, 24(1), 266-280. Retrieved from http://www.waeaonline.org/publications/jare

Watson, P., Cooke, S., Kay, D., \& Alward, G. (2015). A method for improving economic contribution studies for regional analysis. Journal of Regional Analysis and Policy, 45(1), 1-15. Retrieved from https://irap.scholasticahq.com 
Watson, P., Kay, D., Alward, G., Cooke, S., \& Morales, A. (2017). A method for evaluating the economic contribution of a local food system. Journal of Agricultural and Resource Economics, 42(2), 180-194. Retrieved from http://www.waeaonline.org/publications/jare

Woodbury, M. A. (1950). Inverting modified matrices (Memorandum Report No. 42). Princeton, New Jersey: Statistical Research Group, Princeton University. 


\section{A. Appendix}

This appendix is provided for the interested reader to demonstrate how the approach was carried out using IMPLAN. We incorporate the relevant literature motivating the approach as well as technical references for the procedures carried out. This study (above) provides a real-world application of the approach in which an LFS consists of parts of multiple states and includes a high level of diversity in terms of food production, ranging from conventionally produced row crops to specialty crops. We also include a hypothetical scenario that a typical policy make may pose and consider different factors and consequences of such a scenario.

\section{A1. Measuring Local Food Benchmarks}

Quantifying the size of the local food system requires understanding the construction behind the standard I/O model. We start with a standard representation of the regional industry-by-industry social accounting matrix as presented in Watson et al. (2015) and shown in Table A1. In the industry-by-industry specification, commodities are mapped into corresponding industries that produce and purchase those commodities, such that the industry category is representative of the value of commodities transacted. The transactions table underlies most regional I/O models, including IMPLAN, for calculating economic impacts. More importantly for this analysis, the transactions table shows, with a significant level of detail, the annual transactions that firms and households make with supplying industries. For the three-industry example provided here, reading down the industry column shows what the corresponding industry purchased for the production of $q_{i}$ output. Industry 1 purchases $z_{11}$ from its own industry, $z_{21}$ from industry $2, z_{31}$ from industry 3 , pays out $v_{1}$ to households and to indirect business taxes, and purchases $m_{1}$ imports as intermediate inputs. The sum of these purchases will equal the industry's output, $q_{1}$, as the sum of all intermediate purchases (industry sales and imports) and payments to factors and profits (incomes).

Table A1. Compacted Example of Industry-by-Industry Input-Output Table

\begin{tabular}{|c|c|c|c|c|c|c|c|}
\hline & & \multicolumn{3}{|c|}{ Industry Purchases } & \multirow[b]{2}{*}{ Consumption } & \multirow[b]{2}{*}{ Exog. Demands } & \multirow[b]{2}{*}{ Totals } \\
\hline & & 1 & 2 & 3 & & & \\
\hline \multirow{3}{*}{$\begin{array}{c}\text { Industry } \\
\text { Sales }\end{array}$} & 1 & $z_{11}$ & $z_{12}$ & $z_{13}$ & $c_{1}$ & $x_{1}$ & $q_{1}$ \\
\hline & 2 & $z_{21}$ & $z_{22}$ & $z_{23}$ & $c_{2}$ & $x_{2}$ & $q_{2}$ \\
\hline & 3 & $z_{31}$ & $z_{32}$ & $z_{23}$ & $c_{3}$ & $x_{3}$ & $q_{3}$ \\
\hline \multicolumn{2}{|c|}{ Income } & $v_{1}$ & $v_{2}$ & $v_{3}$ & & $x_{4}$ & $v$ \\
\hline \multicolumn{2}{|c|}{ Imports } & $m_{1}$ & $m_{2}$ & $m_{3}$ & $m_{4}$ & & $m$ \\
\hline \multicolumn{2}{|c|}{ Totals } & $q_{1}$ & $q_{2}$ & $q_{3}$ & $c$ & $x$ & $q$ \\
\hline
\end{tabular}

Reading across an industry row shows who buys a given industry's output. Here, industry 1 sells $z_{11}$ to itself, $z_{12}$ to industry 2 , and $z_{13}$ to industry 3 as intermediate inputs to their production. It also sells $c_{1}$ to local consumers and exports $x_{1}$ outside the region to other domestic or global markets. Since every industry's expenditure represents another industry's revenue, the value of any industry's production will equate with the value of its sales.

By dividing all cells by their corresponding column totals, cell entries indicate the share of output, local consumption, and regional exports that make up each corresponding sector. These are the technical coefficients underlying a standard regional economic impact model. The industry column vectors of the table of technical coefficients represent unit production functions, or how much of each input is necessary to produce US $\$ 1$ 's worth of output. From this, one can deduce that a decrease in imports will necessarily result in an increase in some combination of other industry inputs, such that the column continues to sum to one.

IMPLAN derives regionalized technical coefficients from the national technical coefficients, regionalized 
by the share of inputs supplied locally (IMPLAN Group LLC, 2015). That is, the regional technical coefficients are national unit production functions adjusted for local availability. IMPLAN Pro. 3.0 introduced improved methods for estimating the local shares, or regional purchase coefficients (RPCs), based on a doubly constrained transportation-gravity model specification (Lindall, Olson, \& Alward, 2006). The resulting RPCs for each commodity are applied across their respective rows of the national table of technical coefficients. This equal treatment of all purchasing sectors poses a shortcoming of using I/O models not based surveys to estimate sectors' contributions to the local economy (Round, 1983), as doing so implies that households purchase from local sources in equal shares as intermediary purchasers. Economists have found no satisfactory way of relaxing this assumption without incurring the high costs of surveying buyers and sellers in the study region (Stevens, Treyz, Ehrlich, \& Bower, 1983). However, augmenting the base transactions table with surveys of selected sectors has proven to be a viable approach to differentiating local food from conventional foods in estimating impacts (Jablonski \& Schmit, 2016; Swenson, 2010).

To exemplify how the industry-by-industry transactions table shown in Table A1 can quantify local food transactions, suppose the three industries in this example represent agricultural production (industry 1), food processing (2), and retail trade (3). As described in Miller et al., (2015), three equations can represent the value of local foods that are retained in the region as unprocessed or processed direct sales to consumers or as intermediated sales through more conventional channels.

To illustrate, consider that agricultural producers $\left(z_{11}\right)$ sell to both food processors $\left(z_{12}\right)$ and directly to consumers $\left(c_{1}\right)$. Treatment of retail intermediation through retail channels is described below. Farm sales of local food can be estimated as the row sum of purchases as follows:

\section{(1) Local Direct Sales $=z_{11}+z_{12}+c_{1}$}

Processors take agricultural inputs and generate sales of processed foods. However, processors also purchase inputs including non-agricultural inputs like packaging and energy as well as imported agricultural inputs in the production of final goods. The goal is to account for the share that is supplied by local agricultural producers. Local food's share of food processor contribution (or the value added as this stage) is captured by the first term in equation 2 . Since only the share that is not exported should be retained as local, the local purchases of manufacturing contribution is multiplied by the share of processed output that remains local, as captured in the second term in equation $2 .{ }^{9}$

$$
\text { (2) Local Processed VA=( } \left.\frac{z_{12}}{q_{2}-v_{2}} v_{2}\right)\left(\frac{q_{2}-x_{2}}{q_{2}}\right)
$$

The value of trade transactions is captured in the final equation. Trade transactions require special considerations, as the trade sector transactions $z_{13}$ only estimates the margins the trade sectors earn in handling goods for final sale. For fresh produce sales, the trade revenue is simply $z_{13}$. Capturing the retail margin value of local processed foods traded requires capturing retail margins of locally grown produce purchased by consumers and the share of retail margins earned from the sale of processed foods that are sourced locally:

$$
\text { (3) Local Trade }=z_{13}+\left(\frac{z_{12}+\text { Local Processed VA }}{q_{2}}\right) z_{23}
$$

\footnotetext{
${ }^{9}$ For clarity, this is not a conventional definition of local food in the context of what some consumers may expect from farmers markets. Instead, it is strictly a geographic definition. However, the concept of local food is evolving due in part to the inclusion of processed local foods, intermediaries, and holistic approaches to estimate the value of local foods systems (Miller et al., 2015).
} 
This example illustrates the extent of measuring local agricultural production that remains in the local economy, that is, the output of the LFS. Using fixed ratios of employment to output by sector will provide employment direct effects of the LFS. Alternative definitions of local can be incorporated through modifications of production functions that reflect the selected definition of local foods as described in Thilmany McFadden et al. (2016).

\section{A2. Measuring Economic Contribution of Local Foods}

Cooke and Watson (2011) and Watson et al. $(2015,2017)$ used the social accounting matrix as the basis for valuing the economic contributions of LFSs. Methods drew on approaches for measuring the changes in interregional transactions from import substitution. Starting with Cooke and Watson (2011), the framework establishes a standard I/O economic impact specification derived from Table A1 as:

\section{(4) $\mathbf{q}=(\mathbf{I}-\mathbf{A})^{-1} \mathbf{x}$}

In equation 4, $\mathbf{q}$ is an $\mathrm{N}$ vector of total outputs that is reproduced as some multiple of the $\mathrm{N}$ vector of exogenous demands, $\mathbf{x}$. The NxN matrix $(\mathbf{I}-\mathbf{A})^{-1}$ is derived from Table A1, where the $\mathbf{I}$ matrix is an NxN identity and the $\mathbf{A}$ matrix of technical coefficients have elements $a_{i j}=z_{i j} / q_{j}$. This matrix is also called the Leontief inverse (or $\mathbf{L}$ ) and the total requirements matrix because summing down a column shows the total value of direct and secondary inputs required for generating US $\$ 1$ of the corresponding sector output. The vector of industry I/O multipliers, $\mathbf{k}$, is calculated as the corresponding column sums of the $\mathbf{L}$ matrix. That is, the model structure is invariant to changes in production.

Changes in local purchase behavior, however, change the underlying structure of the local economy and will exhibit changes in the multipliers. For example, from Table A1, if industry 2 increases local purchases from industry 1 then $\Delta z_{12}>0$ and $\Delta m_{2}<0$. In other words, the local inter-industry purchases deepen, reducing leakages from the economy. This deepening of the local economy decreases reliance on imports indicated as $\Delta \mathbf{k} \geq \mathbf{0}$. From this framework, a new multiplier for industry $1\left(k_{1}+\Delta k_{1}\right)$ multiplied by the change in local demand $\left(\Delta z_{12}\right)$ to provide estimates of the economic impact of changes in local food demand. For small changes in local demand, $\Delta k_{1}$ will be small.

This approach gets more complicated when attempting to apply it to changes in local final demands. Local purchases for final consumption compete against imported goods for final consumption and exhibit an element of import substitution. Since it is for final consumption, such purchases should not feed back into the local economy as changes in the production process. Hence, institutional purchases of locally sourced foods should be treated as changes in exogenous demand, subject to fixed multipliers (Miller et al., 2015).

Watson et al. $(2015 ; 2017)$ provided another framework for interpreting industry contribution to local economies. By diagonalizing the vector of final demands in equation 4 , the output vector is transformed to an NxN matrix of outputs.

\section{(5) $\overline{\mathbf{q}}=\mathbf{L} \cdot \hat{\mathbf{x}}$}

In equation 5, the symbol $\wedge$ above the vector of exogenous demands denotes the $\mathrm{NxN}$ diagonalized vector $\mathbf{X}$, where each value $x_{i}$ is placed on the diagonal as $\hat{x}_{i i}$, and off-diagonal elements are set to zero. Additionally, a bar $\left(^{-}\right)$is added to the $\mathbf{q}$ matrix to delineate it from the vector of total outputs, $\mathbf{q}$. According to Waters, Weber, and Holland (1999), a sector's export base is the component of a sector's output that fulfills export production, and can be estimated as the column sum of all production sectors of $\overline{\mathbf{q}}$ (industry sectors), as:

\section{(6) $E B_{i}=\sum_{j} \bar{q}_{i j}$, where $j \in$ industry sectors}


Alternatively, reading across the $\overline{\mathbf{q}}$ rows will reproduce the vector of total outputs $\mathbf{q}$. A sector's export base can be larger or smaller than the sector's total output because its contribution to the export base captures the intermediate input's contribution. From Table A1, subtracting the column of exogenous (export) demands $\mathbf{X}$ from the total output column $\mathbf{q}$, will provide a measure of contributions to import substitutions, that is, a vector of supply to local uses. Comparing the value of export base to the values of import substitutions indicates the contribution a sector makes to wealth creation in the region (Watson et al., 2015). Thus, wealth is created by exporting and generating an inflow of payments, while selling to local uses averts an outflow of funds for importing goods. ${ }^{10}$

\section{A3. Measuring Net impacts of Local Food Sales}

It is important to recognize that directing current production to local uses has an opportunity cost of not directing that output to exports (Conner et al., 2008; Swenson, 2009; Thilmany McFadden et al., 2016). It may be tempting to model the economic impacts of local food sales from receipts of farmers markets, but that overlooks the fact that by selling through the farmers market, the grower did not sell the same produce through other channels. However, the impacts should be the net of the export value foregone (Swenson, 2009). At the same time, it may be that local production may substitute for exported production if new land enters into the production framework. This consideration, is outside the scope of our approach but could be incorporated into future applications if changes in land use are known. For this study, we highlight here that the net economic effects of increasing LFSs can be estimated in two parts. The first part is the associated impacts of reducing food sector exports. The second is the increased local uses of the food sector output.

The export impacts of a change in output can be calculated with the standard I/O equation as follows:

$$
\text { (7) } \Delta \mathbf{Q}^{E}=\mathbf{L}^{\mathbf{0}} \cdot \Delta \mathbf{F}^{E}
$$

where, $\mathbf{L}^{\mathbf{0}}$ is the baseline Leontief inverse, $\Delta \mathbf{F}^{\boldsymbol{E}}$ is the value of direct sales (in this case change in export sales), and $\Delta \mathbf{Q}^{\boldsymbol{E}}$ is the vector of the total change in output required for generating $\Delta \mathbf{F}$ final sales, including direct and secondary effects. Equation 7 is the standard export-oriented economic impact relationship, where the Leontief matrix reflects fixed local expenditure patterns. Alternatively, increasing local demand shifts the relationships that underlie the Leontief inverse. The impact of an increase in local demand, holding exports constant, can be estimated as:

\section{(8) $\Delta \mathbf{Q}^{L}=\mathbf{L}^{1} \cdot \Delta \mathbf{F}^{L}$,}

where $\mathbf{L}^{\mathbf{1}}$ is the modified Leontief inverse reflecting a greater share of industry and consumer purchases of food imports being supplied by local producers, $\Delta \mathbf{F}^{\boldsymbol{L}}$ is the value of output diverted to local consumption, and $\Delta \mathbf{Q}^{\boldsymbol{L}}$ is the vector of total change in output required for generating $\Delta \mathbf{F}^{\boldsymbol{L}}$ in output.

Combining equations 7 and 8 provides an estimate of a one-to-one shift from exports to local sales. The net effects, $\mathbf{N E}$, are calculated as combined impacts such that:

$$
\text { (9) } \mathbf{N E}=\Delta \mathbf{Q}^{L}+\Delta \mathbf{Q}^{E}=\mathbf{L}^{1} \cdot \Delta \mathbf{F}^{L}+\mathbf{L}^{0} \cdot \Delta \mathbf{F}^{E}
$$

Modeling a simple diversion of exports to local sales results in an additive inverse equality as:

\footnotetext{
10 The economic base drives the local economy (Waters, Weber, \& Holland, 1999), as the causal association is from basic to non-basic economic activity. This approach to assessing the sector contribution to economic activity, however, is subject to the critiques of economic base theory, as summarized in Tiebout (1956).
} 


\section{(10) $\Delta \mathbf{F}^{L}=-\Delta \mathbf{F}^{E}$}

Substituting equation 10 for $\Delta \mathbf{F}^{\boldsymbol{E}}$ into equation 9 and simplifying provides:

$$
\text { (11) } \mathbf{N E}=\left(\mathbf{L}^{\mathbf{1}}-\mathbf{L}^{\mathbf{0}}\right) \cdot \Delta \mathbf{F}^{L}
$$

The net effect of diverting production from export sales to local uses is the change in the Leontief inverse multiplied by the value of goods diverted to local use (Miller \& Blair, 2009, p. 574). Given that changes in local uses are positive, the multipliers associated with $\mathbf{L}^{\mathbf{1}}$ will be larger than those of $\mathbf{L}^{\mathbf{0}}$, yielding a positive net impact. The total aggregate impacts are simply the sum of industry net effects $\left(\sum_{i} N E_{i}\right)$.

\section{A4. Inverse Importance Coefficients}

Equation 11 provides a basis for understanding the potential impact of increasing local demand, but in the context that all users increase their purchases in equal proportion to current expenditures. ${ }^{11} \mathrm{~A}$ policy analyst may be interested in the relative impacts of targeting sectors as purchasers of locally sourced commodities. In other words, shifting local demand from imports to local suppliers may be more impactful for some sectors than others. From an economic development planning perspective, this is analogous to identifying the intermediate uses of locally sourced goods that will generate the largest economic impact. This line of inquiry follows that of "important coefficients" of a matrix inverse (Miller \& Blair, 2009, p. 567). From Table A1 and following Cooke and Watson (2011), an increase in industry 2's purchases of industry 1 output, $\Delta z_{12}>0$, may generate relatively larger or smaller secondary impacts than, say, a change in industry 3 purchases from industry 2, $\Delta z_{32}$. By assessing the relative size of economywide impacts from each successive $z_{i j}$, one can assess the relative merit of focusing economic development efforts on key industry linkages. ${ }^{12}$

Important coefficients underlying the social accounting matrix (SAM) are identified by the proportional change in the size of the largest impacted total requirements matrix elements to the change in a direct requirements matrix element. Given a technical requirements matrix $\mathbf{A}$ derived from a transactions table $\mathbf{Z}$, a change in any set of elements produces a new technical requirements matrix $\mathbf{A}^{*}$. The total requirements matrix $\mathbf{L}$ is derived as:

$$
\text { (12) } \mathbf{L}=(\mathbf{I}-\mathbf{A})^{-1}
$$

The post-change total requirements matrix is calculated as:

$$
\text { (13) } \mathbf{L}^{*}=\left(\mathbf{I}-\mathbf{A}^{*}\right)^{-1}
$$

Proportional changes in the elements of $\mathbf{L}$ are calculated as:

$$
\text { (14) } \mathbf{P}=100 \cdot\left(\mathbf{L}^{*}-\mathbf{L}\right) \oslash \mathbf{L}
$$

where $\oslash$ denotes elementwise division. Equation 14 calculates an $\mathrm{NxN}$ matrix of percent changes. Iterating through each element of the technical coefficient matrix, Hewings (1984) suggests that a coefficient generates

\footnotetext{
${ }^{11}$ Here, the net impact calculation is analogous to an increase in the sector's regional purchase coefficient (RPC), as applied equally to all purchasing sectors.

12 A survey of the research in this area can be found in Casler and Hadlock (1997). This analysis follows Sherman and Morrison (1950) and Woodbury (1950) in assigning changes to an inverse matrix from changes in its primal form. Miller and Blair (2009) show the equivalent application in $\mathrm{I} / \mathrm{O}$ modeling.
} 
a significant change in the economy if it generates at least one $\mathbf{P}$ coefficient whose absolute value exceeds some predetermined benchmark, $\beta$, which could be established by expectations given prior literature. $\mathbf{P}_{r s}$ is significant if $p_{i j}>\beta$ for all $i=1, \ldots, N$ and $j=1, \ldots, N$, where $r$ and $s$ represent the row and column of the iterated element of the $\mathbf{A}$ matrix. Alternatively, important coefficients can be identified by comparing the percent change in resulting multipliers, as:

$$
\text { (15) } \mathbf{P M}=100 \cdot \mathbf{i}^{\prime} \cdot\left(\left(\mathbf{L}^{*}-\mathbf{L}\right) \oslash \mathbf{L}\right) \text {. }
$$

In equation 15, the vector $\mathbf{i}$ is an $\mathrm{N}$ column summing vector of ones and $\mathbf{P M}$ is a $1 \mathrm{xN}$ vector of the percent change in the size of sector multipliers. A change in one technical coefficient, $a_{r s}$, will result in changes in all sector multipliers. To gauge overall influence in the regional economy, a weighted average of the percent change in $\mathbf{P M}$ coefficients is calculated as:

$$
\text { (16) } A P M=\sum_{j=1}^{N} P M_{j} \cdot\left(Q_{j} / Q\right)
$$

where $A P M$ is a scalar aggregate percent change in multipliers, and $Q=\sum_{i}^{N} Q_{i}$. The term in parentheses represents the weights of industry shares of total industry output. Larger values of APM denote changes in the technical coefficients that generate larger overall changes in regional output through indirect and induced effects. 